Article

\title{
Analyzing the Fitting of Novel Preformed Osteosynthesis Plates for the Reduction and Fixation of Mandibular Fractures
}

\author{
Marc Anton Fuessinger ${ }^{1, *}$, Mathieu Gass ${ }^{1}$, Caroline Woelm ${ }^{1}$, Carl-Peter Cornelius ${ }^{2}$, Ruediger M. Zimmerer ${ }^{3}$, \\ Philipp Poxleitner ${ }^{1}$, Stefan Schlager ${ }^{1}$ and Marc Christian Metzger ${ }^{1}$ (D) \\ 1 Department of Oral and Maxillofacial Surgery, University Freiburg Hugstetterstr, 55, \\ 79106 Freiburg, Germany; mathieu.gass@uniklinik-freiburg.de (M.G.); caroline.woelm@t-online.de (C.W.); \\ philipp.poxleitner@uniklinik-freiburg.de (P.P.); stefan.schlager@anthropologie.uni-freiburg.de (S.S.); \\ marc.metzger@uniklinik-freiburg.de (M.C.M.) \\ 2 Department of Oral and Maxillofacial Surgery, University Munich Lindwurmstr, 2a, \\ 80137 Munich, Germany; peter.cornelius@med.uni-muenchen.de \\ 3 Department of Oral and Maxillofacial Surgery, School Hanover Carl-Neuberg-Str. 1, \\ 30625 Hannover, Germany; zimmerer.ruediger@med.uni-leipzig.de \\ * Correspondence: marc.anton.fuessinger@uniklinik-freiburg.de
}

check for updates

Citation: Fuessinger, M.A.; Gass, M.; Woelm, C.; Cornelius, C.-P.; Zimmerer, R.M.; Poxleitner, P.; Schlager, S.; Metzger, M.C. Analyzing the Fitting of Novel Preformed Osteosynthesis Plates for the Reduction and Fixation of Mandibular Fractures. J. Clin. Med. 2021, 10, 5975. https://doi.org/ $10.3390 / \mathrm{jcm} 10245975$

Academic Editors:

Gianrico Spagnuolo and

Mieszko Wieckiewicz

Received: 21 October 2021

Accepted: 14 December 2021

Published: 20 December 2021

Publisher's Note: MDPI stays neutral with regard to jurisdictional claims in published maps and institutional affiliations.

Copyright: (c) 2021 by the authors. Licensee MDPI, Basel, Switzerland. This article is an open access article distributed under the terms and conditions of the Creative Commons Attribution (CC BY) license (https:/ / creativecommons.org/licenses/by/ $4.0 /)$.

\begin{abstract}
Purpose: The known preformed osteosynthesis plates for the midface are helpful tools for a precise and fast fixation of repositioned fractures. The purpose of the current study is to analyze the precision of newly developed prototypes of preformed osteosynthesis plates for the mandible. Methods: Four newly designed preformed osteosynthesis plates, generated by a statistical shape model based on 115 CT scans, were virtually analyzed. The used plates were designed for symphyseal, parasymphyseal, angle, and condyle fractures. Each type of plate has three different sizes. For analysis, the shortest distance between the plate and the bone surface was measured, and the sum of the plate-to-bone distances over the whole surface was calculated. Results: A distance between plate and bone of less than $1.5 \mathrm{~mm}$ was defined as sufficient fitting. The plate for symphyseal fractures showed good fitting in $90 \%$ of the cases for size $\mathrm{M}$, and in $84 \%$ for size L. For parasymphyseal fractures, size S fits in $80 \%$, size $\mathrm{M}$ in $68 \%$, and size $\mathrm{L}$ in $65 \%$ of the cases. Angle fractures with their specific plate show good fitting for size S in $53 \%$, size $\mathrm{M}$ in $60 \%$, and size $\mathrm{L}$ in $47 \%$. The preformed plate for the condyle part fits for size $\mathrm{S}$ in $75 \%$, for size $\mathrm{M}$ in $85 \%$, and for size $\mathrm{L}$ in $74 \%$ of the cases. Conclusion: The newly developed mandible plates show sufficient clinical fitting to ensure adequate fracture reduction and fixation.
\end{abstract}

Keywords: mandibular fractures; preformed osteosynthesis plates; virtual analysis

\section{Introduction}

Maxillofacial injuries are found to be among the major health problems worldwide, with their epidemiology varying widely in different countries [1-3]. Maxillofacial fractures occur in a significant proportion of trauma patients as a result of the prominent and exposed position of the head, and they have been increasing over the past decades [4]. The fractures are usually associated with dysfunctions in communication (speech and facial expressions), nutrition, breathing, hearing and vision, and with cosmetic consequences, causing emotional distress [5]. In the literature, the incidence of mandibular fractures is found to be from $65 \%$ to $70.5 \%$ of cases, strongly correlating with younger men between 20 and 30 years of age. The main causes of mandibular fractures are traffic accidents (car, bike, or motorcycle), violence, and falls [6]. These mechanisms combined cause over $80 \%$ of the fractures [4,7]. As for the location of the fractures, the literature shows mixed data. The four most common areas are, in that order, the body, the symphysis/parasymphysis, the condyle, and the angle [4,7]. The therapy of a fracture of the mandible can be a conservative or an operative one, depending on factors such as the type of the fracture, the 
anatomic location, and the patient's dental status and age [8-12]. The goal of a surgical approach with osteosynthesis of the fracture is to obtain an exact repositioning of the fracture and the occlusion, as well as an early regaining of functionality [13]. Today, plateand-screw osteosynthesis by means of manually bent plates for mandibular fractures is a standard procedure in routine clinical practice [14-16]. The development in the field of osteosynthesis plates shows two areas. One area is concerned with patient-specific implants, the other with preformed plates that achieve a satisfactory fit based on statistical methods. Both procedures are used in clinical routine. Both procedures have their advantages and disadvantages. Preformed osteosynthesis plates for the mandible and the orbital cavity have shown advantages in terms of fitting accuracy and less time consumption, allowing less invasive approaches with, as a result, fewer surgical risks as, e.g., nerve injury or postoperative hemorrhage [17-21]. Patient-specific implants are highly precise and allow the patient's individual anatomy to be taken into account. The dimensions of the implants can thus be designed to be as stable as necessary and as delicate as possible.

The accuracy of fit of the preformed plates was defined as the main measurement parameter.

A high degree of accuracy of fit is required for clinical use. Manual adaptation should be avoided for the most part, on the one hand, to generate real-time savings and, on the other hand, to prevent perforation through the soft tissues and dislocation of the fracture fragments. Small inaccuracies in the fit can be compensated to a certain extent with the help of angular stable plates and their screws. With the help of this screw technique, the fracture pieces are not pulled to the plate, and the repositioning of the fracture is not disturbed. In addition to the known reconstruction plate of the mandible (MatrixMANDIBLE preformed reconstruction plate), the purpose of this study is to determine the fitting accuracy of preformed osteosynthesis plates for non-comminuted fractures of the mandible by virtual testing.

\section{Materials and Methods}

Virtual testing of four different types of preformed plates in several different sizes (condyle plate, sizes S, M, L; body plate, sizes S, M, L; angle plate, sizes S, M, L; symphysis plate, sizes M, L) was performed on the left and right sides of $50 \mathrm{CT}$ scans of Europeans (30) and Asians (20), using the 3D software GOM Inspect V8 (GOM GmbH, Braunschweig, Germany) [22]. CT scans were performed in cases of suspected midface fracture as a result of a fall, brute force trauma, or accident. In total, 1000 tests were performed (20 plates per patient). Exclusion criteria were pathological findings (fractures, deformities, excessive atrophy) and artifact-causing foreign bodies (dental implants, MFC crowns, screws) to avoid an additional source of error.

\subsection{Design of the Plates}

The shapes and sizes of the plates were designed according to the requirements of the $\mathrm{AO}$ Foundation. For simple linear fractures, the $\mathrm{AO}$ demands load-sharing osteosynthesis. A reduced buttress demands a more stable osteosynthesis. The most frequently applied technique in mandibular fractures is miniplate osteosynthesis combining two plates on the upper and lower border of the mandible. To compensate for the tensile and the compression strain, we in our department prefer the two-plate approach. The upper plate is located in the tension zone, and the lower plate is placed in the pressure zone [23-25]. Following this principle, the suggested plates have an upper and a lower part, stabilized by connectors, which enlarge the possible screw positions and increase the overall stability without increasing the thickness of the plates. The newly introduced plates are connected to each other to heighten the stability without increasing the thickness of the used plates, in order to avoid soft-tissue irritation. By the modified design with connected miniplates, the application range could be enlarged. The preformed plates fitted the strain occurring in the described regions during functioning. The basic elements of the plates are already in clinical use. The combination of two plates and an enlarged material cross-section 
increases the mechanical properties, for which reason a finite element analysis (FEA) was not required for product approval.

The indication for the preformed plates varies from the simple healthy fracture site to multi-fragmentary fracture sites. Only fracture sites with an extensive defect demand reconstruction plates.

To generate the design of the preformed plates, a statistical model was used based on 127 mandibles from clinical CT scans, not included in the test group, with the following distribution regarding ethnicity, sex, and age: Europeans-37 in total, 14 males, 23 females, average age $46.9 \mathrm{y}$, SD age $21 \mathrm{y}$; Chinese- 90 in total, 48 males, 42 females, average age $43.5 \mathrm{y}$, SD age $16 \mathrm{y}$. While the age of the Chinese patients is roughly normally distributed, the European patients show an under-representation in the age interval between 40 and 50 years and an over-representation of patients older than 70 years. After automated segmentation by use of Brainlab iPlan CMF 3.0 (Brainlab, Feldkirchen, Munich, Germany), $3 \mathrm{D}$ triangular surface meshes were generated. To ensure (pseudo)homology throughout the sample, an elastic registration procedure (for further details on registration, see [26]) was employed. All statistical analyses were done with the statistical software R [27] and, specifically, the R packages Morpho, Rvcg [28], and RvtkStatismo [29]. The procedure to compute surfaces representing an optimal shape was identical for all regions: The different regions of interest were defined based on the sample mean and were successively extracted automatically from all registered meshes, exploiting the identical mesh topologies (i.e., corresponding vertex indices). The vertices belonging to this region were then rigidly aligned using a Procrustes registration [30], and a principal component analysis (PCA) was computed on these aligned data. The first PCA represents the major axes of variation. As the data were not standardized regarding size, the first PCA is associated with allometric effects and sexual dimorphism. In order to model these effects, we regressed the shape of this region onto the first PCA, calculating a surface model for the $20 \%, 50 \%$, and $80 \%$ quantiles of the first PCA scores. In that way, the resulting surfaces do not only vary isotropically but also incorporate the shape change associated with size.

\subsection{Analysis of the Accuracy of the Plate}

Analysis of the accuracy was done on 50 additional skulls not employed to establish the statistical shape model. As to the ethnical and gender distribution, 30 skulls were from Europeans (18 males; 12 females) and 20 skulls were from Asians (6 males; 14 females). They were segmented using Voxim IVS Solutions (IVS Technology GmbH i.L., Chemnitz, Germany) based on the Hounsfield segmentation and then exported as STL files.

Initially, a best-fit method was chosen (Figures 1-4). Three points were positioned on every plate, defined as starting points. The same three points were placed on the surface of the mandible as ending points to position the plate and measure the distances between the two surfaces.

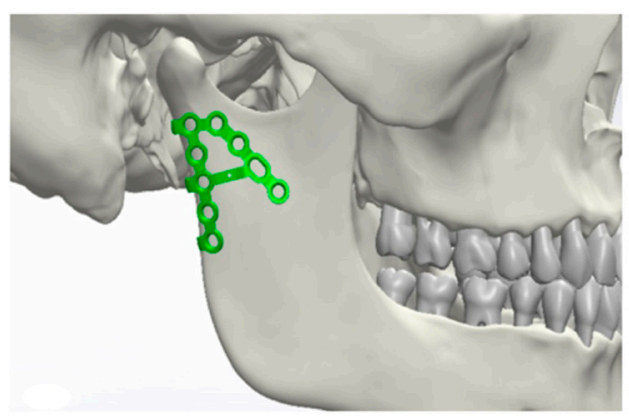

Figure 1. Positioning of the osteosynthesis plates in the area of the condyle. 


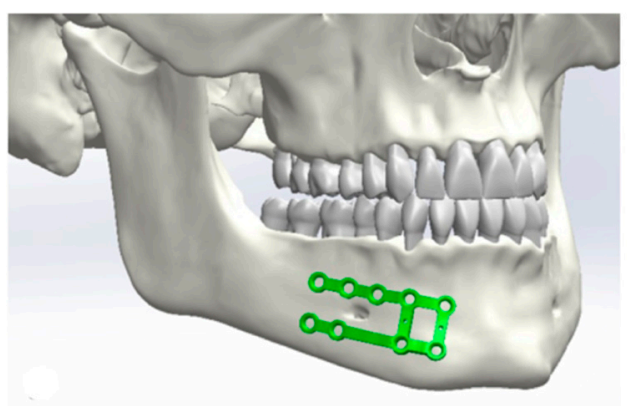

Figure 2. Positioning of the osteosynthesis plates in the area of the body.

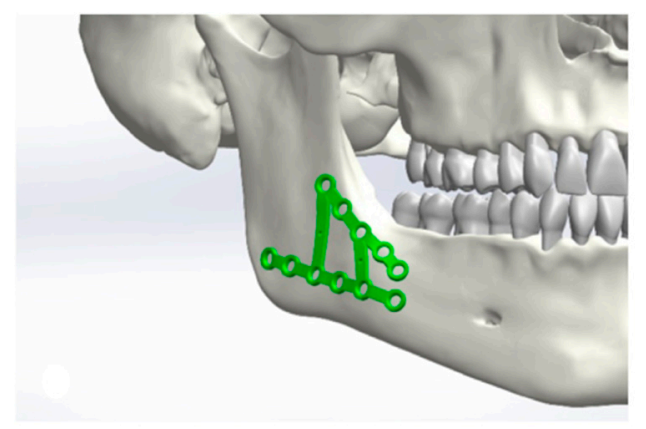

Figure 3. Positioning of the osteosynthesis plates in the area of the angle.

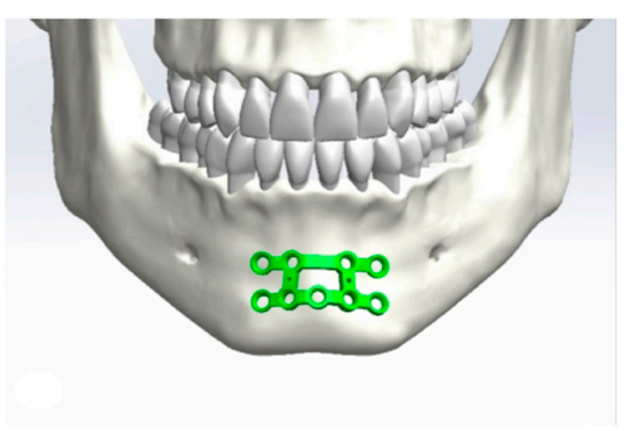

Figure 4. Positioning of the osteosynthesis plates in the area of the symphysis.

In a second step, manual optimization was performed to avoid malpositioning such as overlapping of the foramen mentale or surpassing the lower border of the mandible.

In a third step, with the tool "local best-fit with tolerances", the software corrected the positioning by avoiding the plate diving into the surface of the mandible and by attaining the lowest possible spacing. This procedure was repeated for all 1000 tests. Subsequently, the measurement points were placed on the plates, and the distances between the two surfaces were measured. The software computed, from every point of the polygon on the backside of the plates, the vertical distance to the surface of the mandible (GOM Inspect V8 software) [31]. The measurement result of each testing was automatically saved in an Excel sheet. The statistical evaluation was performed using STATA 13 [32].

\section{Results}

Sufficient fitting of a preformed osteosynthesis plate is defined by the authors as a maximum distance of $1.5 \mathrm{~mm}$ from the bone surface to the plate surface [33]. More than $1.5 \mathrm{~mm}$ distance between plate and bone leads to soft tissue irritation, especially in the field of cranio-maxillo-facial surgery. 
Depending on the plate size, the osteosynthesis plate of the condyle fits in $75 \%$ of the cases for size $\mathrm{L}$, in $85 \%$ of the cases for size $\mathrm{M}$, and in $75 \%$ of the cases for size $\mathrm{S}$. The osteosynthesis plate of the mandible body shows a sufficient fit in $65 \%$ of the cases in size $\mathrm{L}$, in $68 \%$ of the cases in size $\mathrm{M}$, and in $80 \%$ of the cases in size S. In $47 \%$ of the cases in size $\mathrm{L}$, in $60 \%$ of the cases in size $\mathrm{M}$, and in $53 \%$ of the cases in size $\mathrm{S}$, the osteosynthesis plate of the angle shows a sufficient fit. The osteosynthesis plate of the symphysis shows fitting values between $84 \%$ in size $\mathrm{L}$ and $90 \%$ in size $\mathrm{M}$, with no outliers larger than $3 \mathrm{~mm}$. There was no statistically significant difference regarding the different sides of application on the mandible (Table 1).

Table 1. Fitting accuracy in percentage of the preformed osteosynthesis plates of the mandible.

\begin{tabular}{ccccc}
\hline & Size L & Size M & Size S & Total \\
\hline Condyle plate & 74 & 85 & 75 & 78 \\
Body plate & 65 & 68 & 80 & 71 \\
Ramus plate & 47 & 60 & 53 & 53 \\
Symphysis plate & 84 & 90 & - & 87 \\
\hline
\end{tabular}

Ethnic differences only existed regarding the symphysis plate. In the Asian population, the plates fit in $100 \%$ of the cases, whereas in the European population, the plates fit in $78 \%$ of the cases.

The body plate fits for the male population in $81 \%$ of the cases versus $63 \%$ for the female population. Regarding the condyle and the angle plate, no differences could be detected.

In general, the symphysis plate fits best, followed by the condyle plate and the body plate. The angle plate shows worse fitting values compared to the other plate types.

\section{Application of the Plates}

Two clinical cases are included in this article in order to visualize the application of a symphysis and a condyle plate. Figure 5 shows an OPT of a patient with the symphysis plate in place. The fracture of the mandible is approached via an incision in the vestibular fold of the lower jaw. After visual evaluation of the fracture, the fracture is repositioned and the plate is fixated. Because of a lingual gap, a second standard miniplate was applied in addition. Figure 6 shows an OPT of a patient with a combined fracture of the condyle and the parasymphysis.

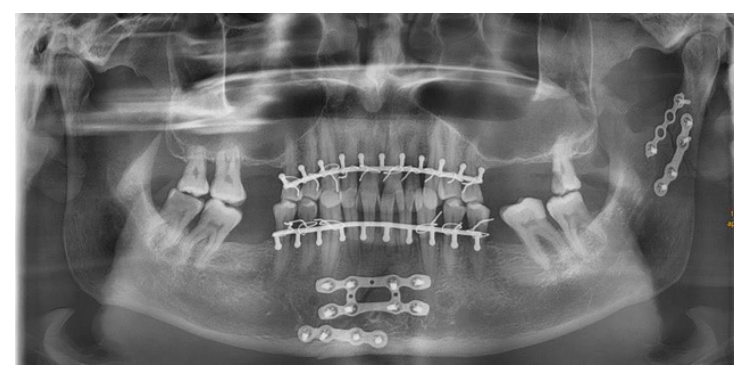

Figure 5. Visualization of the application of the symphysis plate. 


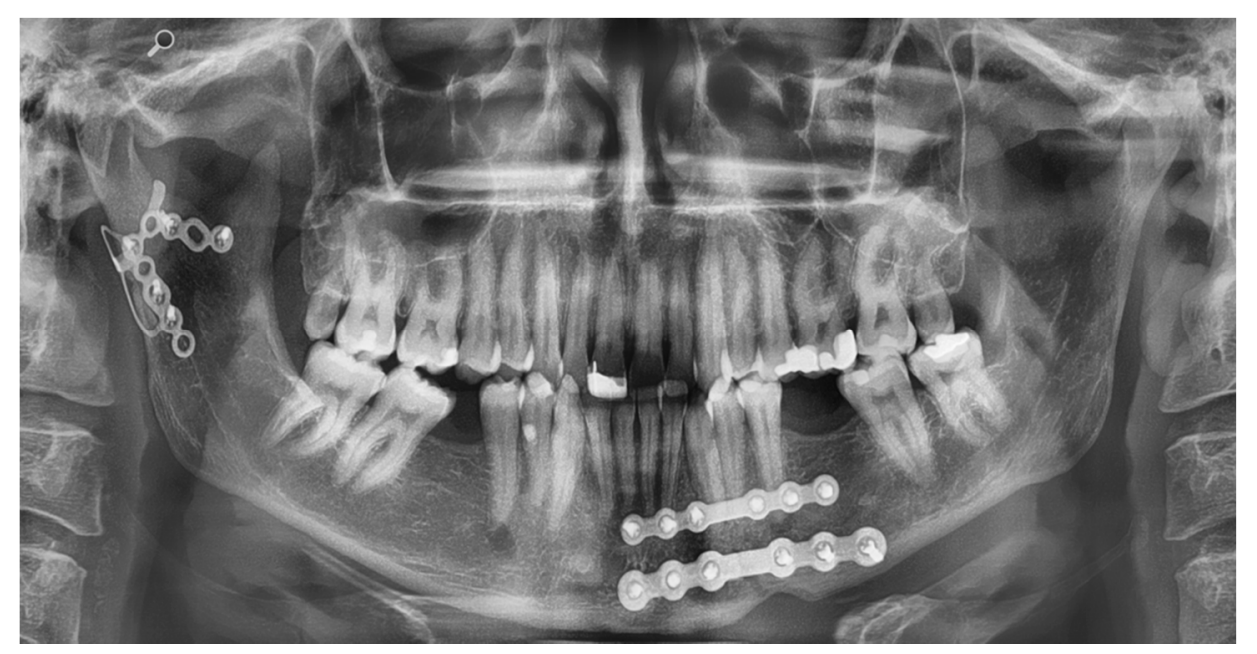

Figure 6. Visualization of the application of the condyle plate, with a modification to hold the upper segment.

\section{Discussion}

Preformed osteosynthesis plates are helpful tools in cranio-maxillofacial surgery. For simple fractures, preformed plates for the orbital cavity and the mandible reduce the time-consuming step of plate bending without worsening the fracture repositioning. Although focused on the orbital cavity, preformed plates provide a higher accuracy of the reconstructed contour and an easier use, and, by reducing the operation time, they reduce the cost [21]. The mandible shows a more complex anatomy. The differences between the sexes as well as the dependence on size are factors for the preformed plates that make standardization and, thus, preforming difficult [34]. The present study was performed virtually as previously described by Chrcanovic et al. [10] in a review in order to obtain a better statement on the accuracy of fit due to the large number of computational options.

In our opinion, the results of the virtual test as shown can also be applied to the plates for the lower jaw, and this was done in previous studies [25,35-38]. In the area of the symphysis, the strong contouring of the plate helps to avoid lingual gaping of the fracture gap [38]. In the area of the condylar process, the preformed plate supports fracture reduction despite the limited overview. In comminuted fractures, the preformed plate helps to reposition the fracture because of its predetermined shape. Studies using preformed plates in comminuted fractures show advantageous results [25,39,40]. Based on a newly developed statistical shape model, preformed panels can be developed for different ethnicities, different age groups, and different genders.

Considering the data basis, a sufficiently large variance in age, gender, and ethnicity was obtained in the present study by using the statistical form model. The number of CT scans used was sufficient to obtain a statistically significant result for interpreting the fitting of the plates. A critical point of our analysis is the first setting of the measurement points. The initial positioning is defined by the manufacturer after consultation of experienced surgeons in the developer team. The main positioning of the plates is then done automatically by the freeware, simply by identifying the shortest distance between the plate and the bone surface. Manual repositioning was only necessary in cases when the automated positioning algorithm had put the plates next to sensitive anatomical structures. The possible bias of virtual analysis based on manual positioning is reduced due to this automated algorithm, while former studies used only the manual positioning approach [41].

The design of the plates is critical for their clinical application. The design is based on observations on clinically used osteosynthesis plates for mandibular fractures. In the condyle, body, and symphysis area, the use of two plates is generally accepted [25,42]. In non-displaced simple fractures of the mandibular angle, the miniplate fixation on the oblique ridge according to Champy is the standard method. The Champy technique 
is a minimally invasive and fast method. In this case, a preformed plate would not be advantageous [43].

In comminuted or more displaced fractures, application of two plates supports the surgeon in improving the bone buttressing and alignment. For this reason, the design of the angle plate employs two connected plates according to the osteosynthesis principles of the AO Foundation. Under load-bearing conditions in complex fracture patterns, preformed reconstruction plates are already in clinical use and show advantages concerning the repositioning of fractures, a minimized risk of fatigue fractures, and reduced operation times $[19,39]$.

In our study, in about $72 \%$ of the cases, the preformed plates could be applied in the clinic. Based on individual surgical experience and former studies, the optimal distance between bone and osteosyntheses plate should be $2 \mathrm{~mm}$ or less [33,44,45]. In the shown study, the authors defined a maximum distance between the bone surface and the plate surface of $1.5 \mathrm{~mm}$. The distance limit of $1.5 \mathrm{~mm}$ from the bone to the plate surface is clinically relevant. Gaps larger than $1.5 \mathrm{~mm}$ will lead to soft-tissue irritation and the danger of wound infection by soft-tissue perforation. At the defined limit of $1.5 \mathrm{~mm}$, the clinical precision for fracture repositioning is sufficient, especially when using locking screws to hold the bone in the correct position without putting pressure on the fracture ends.

The availability of the preformed plates is a big advantage over patient-specific implants (PSI), which constitute the most precise but also the most expensive method in bone reconstruction. In addition, preformed plates can also be used in emergency cases. In only $21 \%$ of the cases, small adjustments have to be done, which means reduced bending and, consequently, a lower risk of fatigue fractures. In contrast to off-the-shelf plates, the amount of bending for the worst-fitting plates is still reduced. In $69.4 \%$ of cases, the fit is perfect. The shown gender discrepancy in the results for the angle plate is due to the developmentally stronger expression of the masseteric tuberosity.

Regarding the results, size L shows the worst fitting of all plates. Sizes $M$ and S show better fitting; thus, size L plates need some adjustments before these prototypes can be used regularly. Improving the fitting for larger plates requires more information during the construction process. The larger the plate, the more prominent the contours of the mandible will be. One strategy could be to change the position of the plate to avoid the direct localization on the strong curvatures such as the tuberositas. Another possibility could be to integrate more data of larger mandibles before the construction process. Later, the selection of the respective plate is clinically comparable to that of the preformed orbital plates, based primarily on the gender and secondarily on the body size. Women mostly receive a plate of size $S$, men mostly a plate of size $M$.

\section{Conclusions}

The presented study shows the possibility to use preformed osteosynthesis plates in a precision sufficient for clinical use.

Apart from the clinically sufficient precision, it is conceivable that region- and genderspecific preformed plates will be designed by the statistical model. An increase in precision is thus easily feasible.

The cost side is also attractive due to the use of an open source code to calculate the statistical shape model [46]. In addition to manufacturing costs, the importance of the intraoperative efficacy of preformed plates becomes clear when considering the number of mandibular fractures per year. A reduction in operating time through the use of preformed plates is clinically and economically relevant for the patient and the hospital in general [19-21,39,47].

3D printing will challenge the preformed plates in the future. Still, the virtual reconstruction of a mandibular fracture by a manual approach is technically demanding and time consuming [48]. The preformed plates will be a kind of bridging technology until virtual fracture reconstruction is automated and in-house 3D printing is sufficiently fast. Currently, the cost-benefit ratio is much better than fully individualized plates, and the time in which the plates can be used is unrivaled. 
Author Contributions: Data curation, C.W.; Formal analysis, S.S.; Funding acquisition, M.C.M.; Writing-original draft, M.A.F.; Writing-review and editing, M.G., C.-P.C., R.M.Z. and P.P. All authors have read and agreed to the published version of the manuscript.

Funding: This research received no external funding.

Institutional Review Board Statement: The study was conducted according to the guidelines of the Declaration of Helsinki, and approved by the Institutional Review Board of University Freiburg (EK-Freiburg450-15; 2018). All applicable international, national and/or institutional guidelines for the care and use of animals were followed.

Informed Consent Statement: Patient consent was waived due to using anonymized CT Data.

Data Availability Statement: The data presented in this study are available on request from the corresponding author. The data are not publicly available due to intellectual property.

Conflicts of Interest: There is no conflict of interest with a manufacturer of osteosynthesis materials regarding the results of the study. The authors have no consulting activity with a manufacturer of osteosynthesis materials. The prototypes of the preformed plates used in the patient cases were produced by KLS Martin, Tuttlingen, Germany.

\section{References}

1. Adi, M.; Ogden, G.R.; Chisholm, D.M. An analysis of mandibular fractures in Dundee, Scotland (1977 to 1985). Br. J. Oral Maxillofac. Surg. 1990, 28, 194-199. [CrossRef]

2. Boffano, P.; Kommers, S.C.; Karagozoglu, K.H.; Forouzanfar, T. Aetiology of maxillofacial fractures: A review of published studies during the last 30 years. Br. J. Oral Maxillofac. Surg. 2014, 52, 901-906. [CrossRef]

3. Bormann, K.-H.; Wild, S.; Gellrich, N.-C.; Kokemüller, H.; Stühmer, C.; Schmelzeisen, R.; Schön, R. Five-year retrospective study of mandibular fractures in Freiburg, Germany: Incidence, etiology, treatment, and complications. J. Oral Maxillofac. Surg. 2009, 67, 1251-1255. [CrossRef]

4. Chrcanovic, B.R.; Abreu, M.H.N.G.; Freire-Maia, B.; Souza, L.N. 1,454 mandibular fractures: A 3-year study in a hospital in Belo Horizonte, Brazil. J. Cranio-Maxillofac. Surg. 2012, 40, 116-123. [CrossRef]

5. Bak, M.J.; Doerr, T.D. Craniomaxillofacial fractures during recreational baseball and softball. J. Oral Maxillofac. Surg. 2004, 62, 1209-1212. [CrossRef]

6. Afrooz, P.N.; Bykowski, M.R.; James, I.B.; Daniali, L.N.; Clavijo-Alvarez, J.A. The Epidemiology of Mandibular Fractures in the United States, Part 1: A Review of 13,142 Cases from the US National Trauma Data Bank. J. Oral Maxillofac. Surg. 2015, 73, 2361-2366. [CrossRef]

7. Al-Khateeb, T.; Abdullah, F.M. Craniomaxillofacial Injuries in the United Arab Emirates: A Retrospective Study. J. Oral Maxillofac. Surg. 2007, 65, 1094-1101. [CrossRef]

8. Hlawitschka, M.; Eckelt, U. Clinical, radiological and axiographic examination after conservative functional treatment of intracapsular temporomandibular joint fractures. Mund Kiefer Gesichtschir. 2002, 6, 241-248. [CrossRef]

9. Zachariades, N.; Mezitis, M.; Mourouzis, C.; Papadakis, D.; Spanou, A. Fractures of the mandibular condyle: A review of 466 cases. Literature review, reflections on treatment and proposals. J. Cranio-Maxillofac. Surg. 2006, 34, 421-432. [CrossRef]

10. Chrcanovic, B.R. Open versus closed reduction: Diacapitular fractures of the mandibular condyle. Oral Maxillofac. Surg. 2012, 16, 257-265. [CrossRef]

11. Neff, A.; Kolk, A.; Meschke, F.; Deppe, H.; Horch, H.-H. Small fragment screws vs. plate osteosynthesis in condylar head fractures. Mund Kiefer Gesichtschir. 2005, 9, 80-88. [CrossRef]

12. Koulocheris, P.; Sakkas, N.; Otten, J.-E. Maxillomandibular fixation with Otten mini-hooks. Br. J. Oral Maxillofac. Surg. 2007, 45, 679-680. [CrossRef]

13. Ellis, E.; Miles, B.A. Fractures of the mandible: A technical perspective. Plast. Reconstr. Surg. 2007, 120, 76S-89S. [CrossRef]

14. Sauerbier, S.; Schön, R.; Otten, J.-E.; Schmelzeisen, R.; Gutwald, R. The development of plate osteosynthesis for the treatment of fractures of the mandibular body-A literature review. J. Cranio-Maxillofac. Surg. 2008, 36, 251-259. [CrossRef]

15. Bhatnagar, A.; Bansal, V.; Kumar, S.; Mowar, A. Comparative analysis of osteosynthesis of mandibular anterior fractures following open reduction using "stainless steel lag screws and mini plates". J. Maxillofac. Oral Surg. 2013, 12, 133-139. [CrossRef]

16. De Oliveira, J.C.S.; Moura, L.B.; de Menezes, J.D.S.; Gabrielli, M.A.C.; Pereira Filho, V.A.; Hochuli-Vieira, E. Three-dimensional strut plate for the treatment of mandibular fractures: A systematic review. Int. J. Oral Maxillofac. Surg. 2018, 47, 330-338. [CrossRef]

17. Metzger, M.C.; Schön, R.; Schulze, D.; Carvalho, C.; Gutwald, R.; Schmelzeisen, R. Individual preformed titanium meshes for orbital fractures. Oral Surg. Oral Med. Oral Pathol. Oral Radiol. Endod. 2006, 102, 442-447. [CrossRef]

18. Metzger, M.C.; Vogel, M.; Hohlweg-Majert, B.; Mast, H.; Fan, X.; Rudell, A.; Schlager, S. Anatomical shape analysis of the mandible in Caucasian and Chinese for the production of preformed mandible reconstruction plates. J. Cranio-Maxillofac. Surg. 2011, 39, 393-400. [CrossRef] 
19. Probst, F.A.; Mast, G.; Ermer, M.; Gutwald, R.; Schmelzeisen, R.; Pautke, C.; Otto, S.; Schiel, S.; Ehrenfeld, M.; Cornelius, C.-P.; et al. MatrixMANDIBLE preformed reconstruction plates-A two-year two-institution experience in 71 patients. J. Oral Maxillofac. Surg. 2012, 70, e657-e666. [CrossRef]

20. Schiel, S.; Otto, S.; Pautke, C.; Cornelius, C.-P.; Probst, F.A. Simplified transoral load-bearing osteosynthesis with preformed mandible reconstruction plates. Craniomaxillofac. Trauma Reconstr. 2013, 6, 211-214. [CrossRef]

21. Strong, E.B.; Fuller, S.C.; Wiley, D.F.; Zumbansen, J.; Wilson, M.D.; Metzger, M.C. Preformed vs Intraoperative Bending of Titanium Mesh for Orbital Reconstruction. Otolaryngol. Neck Surg. 2013, 149, 60-66. [CrossRef] [PubMed]

22. 3D Printed Simulation Models Based on Real Patient Situations for Hands-On Practice-Kröger-2017-European Journal of Dental Education-Wiley Online Library. Available online: https:/ / onlinelibrary.wiley.com/doi/abs/10.1111/eje.12229 (accessed on 17 October 2021).

23. De Medeiros, R.C.; Sigua, E.A.; Navarro, P.; Olate, S.; Albergaria Barbosa, J.R. In Vitro Mechanical Analysis of Different Techniques of Internal Fixation of Combined Mandibular Angle and Body Fractures. J. Oral Maxillofac. Surg. 2016, 74, 778-785. [CrossRef]

24. De Medeiros, R.C.; de Moura, A.L.; Sawazaki, R.; Fernandes Moreira, R.W. Comparative in vitro mechanical evaluation of techniques using a $2.0 \mathrm{~mm}$ locking fixation system for simulated fractures of the mandibular body. J. Cranio-Maxillofac. Surg. 2015, 43, 302-305. [CrossRef] [PubMed]

25. Xu, X.; Cheng, K.-J.; Liu, Y.-F.; Fan, Y.-Y.; Wang, J.H.; Wang, R.; Baur, D.A.; Jiang, X.-F.; Dong, X.-T. Experimental validation of finite element simulation of a new custom-designed fixation plate to treat mandibular angle fracture. Biomed. Eng. Online 2021, 20, 15. [CrossRef] [PubMed]

26. Schlager, S.; Rüdell, A. Sexual Dimorphism and population affinity in the human zygomatic structure-Comparing surface to outline data. Anat. Rec. 2017, 300, 226-237. [CrossRef]

27. R Foundation for Statistical Computing. A Language and Environment for Statistical Computing; R Foundation for Statistical Computing: Vienna, Austria, 2008.

28. Schlager, S. Morpho and Rvcg-Shape Analysis in R: R-Packages for Geometric Morphometrics, Shape Analysis and Surface Manipulations. In Statistical Shape and Deformation Analysis; Zheng, G., Li, S., Székely, G., Eds.; Academic Press: Cambridge, MA, USA, 2017; pp. 217-256. ISBN 978-0-12-810493-4. Available online: http://www.sciencedirect.com/science/article/pii/B9780128 104934000110 (accessed on 4 October 2019).

29. Schlager, S. RvtkStatismo: Integrating Statismo and R Using the Vtkstandardmeshrepresenter. 2015. Available online: https:/ /www. researchgate.net/publication/331926435_RvtkStatismo_Integrating_statismo_and_R_using_the_vtkStandardMeshRepresenter (accessed on 21 October 2021).

30. Goodall, C. Procrustes methods in the statistical analysis of shape. J. R. Stat. Soc. Ser. B Methodol. 1991, 53, 285-321. [CrossRef]

31. Ostas, D.; Hedesiu, M.; Roman, C.R.; Cosma, C.; Ciurea, M.; Rotaru, H. Design Workflow for Mandibular Reconstruction. Opportunities and Limitations of In-house Virtual Surgical Planning. J. Med. Biol. Eng. 2021, 41, 482-493. [CrossRef]

32. Acock, A.C. Discovering Structural Equation Modeling Using Stata; Stata Press Books; StataCorp LP: College Station, TX, USA, 2013; Available online: https:/ /ideas.repec.org/b/tsj/spbook/dsemus.html (accessed on 21 October 2021).

33. Ahmad, M.; Nanda, R.; Bajwa, A.S.; Candal-Couto, J.; Green, S.; Hui, A.C. Biomechanical testing of the locking compression plate: When does the distance between bone and implant significantly reduce construct stability? Injury 2007, 38, 358-364. [CrossRef]

34. Chole, R.H.; Patil, R.N.; Balsaraf Chole, S.; Gondivkar, S.; Gadbail, A.R.; Yuwanati, M.B. Association of mandible anatomy with age, gender, and dental status: A radiographic study. Int. Sch. Res. Not. 2013, 2013, 453763. [CrossRef] [PubMed]

35. Tkany, L.; Hofstätter, B.; Petersik, A.; Miehling, J.; Wartzack, S.; Sesselmann, S. New Design Process for Anatomically Enhanced Osteosynthesis Plates. J. Orthop. Res. 2019, 37, 1508-1517. [CrossRef]

36. Schmutz, B.; Wullschleger, M.E.; Kim, H.; Noser, H.; Schütz, M.A. Fit Assessment of Anatomic Plates for the Distal Medial Tibia. J. Orthop. Trauma 2008, 22, 258-263. [CrossRef]

37. Schmutz, B.; Rathnayaka, K.; Albrecht, T. Anatomical fitting of a plate shape directly derived from a 3D statistical bone model of the tibia. J. Clin. Orthop. Trauma 2019, 10, S236-S241. [CrossRef]

38. Ponvel, K.; Panneerselvam, E.; Balasubramanian, S.; Krishna Kumar Raja, V.B. Evaluation of labial versus labio-inferior lines of osteosynthesis using 3D miniplate for fractures of anterior mandible: A finite element analysis with a pilot clinical trial. Chin. J. Traumatol. Zhonghua Chuang Shang Za Zhi 2019, 22, 261-269. [CrossRef] [PubMed]

39. Duttenhoefer, F.; Probst, F.A.; Vach, K.; Cornelius, C.-P.; Zens, M.; Schmelzeisen, R.; Metzger, M.C. Clinical analysis of MatrixMANDIBLE Preformed Reconstruction Plate design. J. Cranio-Maxillofac. Surg. 2017, 45, 1521-1525. [CrossRef]

40. Liu, Y.-F.; Fan, Y.-Y.; Jiang, X.-F.; Baur, D.A. A customized fixation plate with novel structure designed by topological optimization for mandibular angle fracture based on finite element analysis. Biomed. Eng. Online 2017, 16, 131. [CrossRef] [PubMed]

41. Huang, J.I.; Toogood, P.; Chen, M.R.; Wilber, J.H.; Cooperman, D.R. Clavicular anatomy and the applicability of precontoured plates. J. Bone Joint Surg. Am. 2007, 89, 2260-2265. [CrossRef]

42. Datarkar, A.; Tayal, S.; Thote, A.; Galie, M. An in-vitro evaluation of a novel design of miniplate for fixation of fracture segments in the transition zone of parasymphysis-body region of mandible using finite element analysis. J. Cranio-Maxillofac. Surg. 2019, 47, 99-105. [CrossRef] [PubMed]

43. Champy, M.; Loddé, J.P.; Schmitt, R.; Jaeger, J.H.; Muster, D. Mandibular osteosynthesis by miniature screwed plates via a buccal approach. J. Maxillofac. Surg. 1978, 6, 14-21. [CrossRef] 
44. Ronga, M.; Shanmugam, C.; Longo, U.G.; Oliva, F.; Maffulli, N. Minimally Invasive Osteosynthesis of Distal Tibial Fractures Using Locking Plates. Orthop. Clin. N. Am. 2009, 40, 499-504. [CrossRef] [PubMed]

45. Schütz, M.; Südkamp, N.P. Revolution in plate osteosynthesis: New internal fixator systems. J. Orthop. Sci. 2003, 8, 252-258. [CrossRef]

46. Gottsauner, M.; Reichert, T.; Koerdt, S.; Wieser, S.; Klingelhoeffer, C.; Kirschneck, C.; Hoffmann, J.; Ettl, T.; Ristow, O. Comparison of additive manufactured models of the mandible in accuracy and quality using six different 3D printing systems. J. CranioMaxillofac. Surg. 2021, 49, 855-866. [CrossRef] [PubMed]

47. Poxleitner, P.; Steybe, D.; Bublitz, B.; Schlager, S.; Fuessinger, M.A.; Voss, P.J.; Schmelzeisen, R.; Cornelius, C.-P.; Metzger, M. Analysis of the accuracy of a novel preformed osteosynthesis plate for the reduction and fixation of zygomaticomaxillary complex fractures. J. Cranio-Maxillofac. Surg. 2019, 47, 951-958. [CrossRef] [PubMed]

48. Voss, J.O.; Varjas, V.; Raguse, J.D.; Thieme, N.; Richards, R.G.; Kamer, L. Computed tomography-based virtual fracture reduction techniques in bimandibular fractures. J. Cranio-Maxillofac. Surg. 2016, 44, 177-185. [CrossRef] 